\title{
Enhancement of radiation effect using beta-lapachone and underlying mechanism
}

\author{
Ki Jung Ahn, MD1, Hyung Sik Lee, MD², Se Kyung Bai, MD³, Chang Won Song, MD \\ 'Department of Radiation Oncology, Inje University College of Medicine, Busan; ${ }^{2}$ Department of Radiation Oncology, \\ Dong-A University College of Medicine, Busan; ${ }^{3}$ Department of Biochemistry, Kangwon National University, \\ Chuncheon, Korea; ${ }^{4}$ Radiobiology Laboratory, Department of Therapeutic Radiology, \\ University of Minnesota Medical School, Minneapolis, MN, USA
}

\begin{abstract}
Beta-lapachone ( $\beta$-Lap; 3,4-dihydro-2, 2-dimethyl-2H-naphthol[1, 2-b]pyran-5,6-dione) is a novel anti-cancer drug under phase I/II clinical trials. $\beta$-Lap has been demonstrated to cause apoptotic and necrotic death in a variety of human cancer cells in vitro and in vivo. The mechanisms underlying the $\beta$-Lap toxicity against cancer cells has been controversial. The most recent view is that $\beta$-Lap, which is a quinone compound, undergoes two-electron reduction to hydroquinone form utilizing NAD(P)H or NADH as electron source. This two-electron reduction of $\beta$-Lap is mediated by NAD(P)H:quinone oxidoreductase (NOO1), which is known to mediate the reduction of many quinone compounds. The hydroquinone forms of $\beta$-Lap then spontaneously oxidizes back to the original oxidized $\beta$-Lap, creating futile cycling between the oxidized and reduced forms of $\beta$-Lap. It is proposed that the futile recycling between oxidized and reduced forms of $\beta$-Lap leads to two distinct cell death pathways. First one is that the two-electron reduced $\beta$-Lap is converted first to one-electron reduced $\beta$-Lap, i.e., semiquinone $\beta$-Lap (SO) ${ }^{-}$- causing production of reactive oxygen species (ROS), which then causes apoptotic cell death. The second mechanism is that severe depletion of NAD(P)H and NADH as a result of futile cycling between the quinone and hydroquinone forms of $\beta$-Lap causes severe disturbance in cellular metabolism leading to apoptosis and necrosis. The relative importance of the aforementioned two mechanisms, i.e., generation of ROS or depletion of $\mathrm{NAD}(\mathrm{P}) \mathrm{H} / \mathrm{NADH}$, may vary depending on cell type and environment. Importantly, the NQO1 level in cancer cells has been found to be higher than that in normal cells indicating that $\beta$-Lap may be preferentially toxic to cancer cells relative to non-cancer cells. The cellular level of NOO1 has been found to be significantly increased by divergent physical and chemical stresses including ionizing radiation. Recent reports clearly demonstrated that $\beta$-Lap and ionizing radiation kill cancer cells in a synergistic manner. Indications are that irradiation of cancer cells causes long-lasting elevation of NQ01, thereby sensitizing the cells to $\beta$-Lap. In addition, $\beta$-Lap has been shown to inhibit the repair of sublethal radiation damage. Treating experimental tumors growing in the legs of mice with irradiation and intraperitoneal injection of $\beta$-Lap suppressed the growth of the tumors in a manner more than additive. Collectively, $\beta$-Lap is a potentially useful anti-cancer drug, particularly in combination with radiotherapy.
\end{abstract}

Keywords: Beta-Lapachone, Radiation, N001, Radiosensitivity, Radiation damage

Received 1 February 2013, Revised 26 April 2013, Accepted 4 June 2013.

Correspondence: Hyung Sik Lee, MD, Department of Radiation Oncology, Dong-A University College of Medicine, 26 Daesingongwon-ro, Seo-gu, Busan 602-715, Korea. Tel: +82-51-240-5380, Fax: +82-51-248-1510, E-mail: hyslee@dau.ac.kr

(c) This is an Open Access article distributed under the terms of the Creative Commons Attribution Non-Commercial License (http://creativecommons.org/ licenses/by-nc/3.0/) which permits unrestricted non-commercial use, distribution, and reproduction in any medium, provided the original work is properly cited.

www.e-roj.org 


\section{Introduction}

Increasing evidences unequivocally demonstrate that betalapachone ( $\beta$-Lap) is cytotoxic to cancer cells expressing NAD(P)H:quinone oxidoreductase (NO01) [1-18]. Importantly, the level of N001 activity in many cancers is significantly higher than that in normal tissues indicating that cancer cells are more vulnerable to $\beta$-Lap than normal cells. Recent studies clearly demonstrated that $\beta$-Lap is not only cytotoxic by itself but it also potentiates the response of cancer cells to ionizing radiation (IR) [3-6], chemotherapy [7], and hyperthermia [8-11]. The purpose of this article is to review recent reports on the molecular mechanisms underlying the anti-cancer effect of $\beta$-Lap alone or in combination with ionizing radiation.

\section{$\beta$-Lapachone}

$\beta$-Lap was originally obtained from Lapacho trees, which are abundant in South America. Since ancient times, the leaves and bark of Lapacho tree have been used as tea and herbal medicine for various diseases. $\beta$-Lap is now chemically synthesized or prepared in quantities from natural lapachol. $\beta$-Lap exerts a divergent therapeutic activities such as 1) antibacterial and anti-fungal effect, 2) anti-leukemia virus effect, 3) anti-HIV-virus effect, 4) anti-inflammation effect, 5) antipsoriasis effect, and 6) anti-cancer effect $[1,2]$. In recent years, the pharmacological effects of $\beta$-Lap have attracted considerable attention particularly in the cancer research community. $\beta$-Lap has been shown to induce apoptosis in various types of cancer cell lines including prostate, lung, pancreas, colon, ovary and breast cancer [1-18]. Furthermore, $\beta$-Lap has recently been demonstrated to synergistically interact with IR [3-6] and certain chemotherapy drugs [7] and heat shock [8-11] to kill cancer cells. There have been extensive investigations on the mechanisms of the anti-cancer effects of $\beta$-Lap. Cell death caused by $\beta$-Lap was initially attributed to $\beta$-Lap-induced inhibition of topoisomerase I activation $[16,19-22]$ and alteration in topoisomerase II activities $[23,24]$. However, subsequent studies indicated that the $\beta$-Lap-induced alteration in topoisomerase activities observed in cell free system in vitro may not be the major player for $\beta$-Lap-induced cell death in vivo [16]. Other studies indicated that $\beta$-Lap induces apoptosis by interrupting cell cycle progression and that the synergistic interaction of $\beta$-Lap and other cytotoxic agents such as Taxol is caused by inhibition of multiple cell cycle checkpoints [17-18,25]. Further studies have indicated

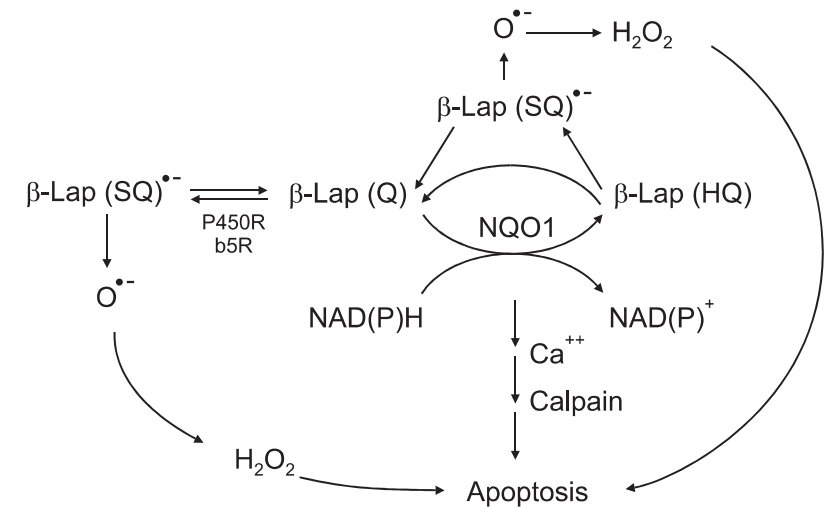

Fig. 1. Signaling pathway of beta-lapachone ( $\beta$-Lap)-induced cell death. $H Q$, hydroquinone; SO, semiquinone; NAD $(P) H$ nicotinamide adenine dinucleotide phosphate.

that futile cycling between oxidized quinone form and twoelectron reduced hydroquinone ( $\mathrm{HO}$ ) form of $\beta$-Lap mediated by NAD(P)H:quinone oxidoreductase (NOO1) is the cardinal process for the killing of cancer cells by $\beta$-Lap (Fig. 1).

\section{NAD(P)H:Quinone Oxidoreductase}

NQ01, also called DT-diaphorase (EC 1.6.99.2), is an obligatory two-electron reductase [26-36]. This flavoprotein enzyme converts quinone compounds in cells to $\mathrm{HO}$ through twoelectron reduction using NADH or $\mathrm{NAD}(\mathrm{P}) \mathrm{H}$ as electron sources (Fig. 1). The hydroquinones are then conjugated with glutathione, glucuronic acid or other moieties and removed from cells $[33,34]$. In a sense, N001 competes with NADPHcytochrome $\mathrm{p}-450$ reductase (P450R) and $\mathrm{NADH}$-cytochrome b5 reductase (b5R), which all causes one electron reduction of quinones to semiquinones [28,37-39]. Unlike the hydroquinone, the semiquinones induce redox cycling and generate reactive oxygen species (ROS), thereby causing oxidative damages to cells. Therefore, the two-electron reduction of quinones to relatively stable hydroquinone by $\mathrm{NOO} 1$ has been suggested to be a detoxification process, and thus N0O1 is regarded as a chemo-preventive enzyme. In this connection, the chemopreventive activity of a variety of synthetic compounds and also dimethyl maleate (DMM) or dimethyl fumarate (DMF), which are found in vegetables and fruits, have been attributed to their ability to upregulate N001 and other phase II detoxifying enzymes in cells [26]. Contrary to above, certain quinone-containing compounds become powerful anti-cancer drugs when they are two-electron reduced by mediation of N001. For example, N001 bioactivates mitomycin C (MMC) 
A

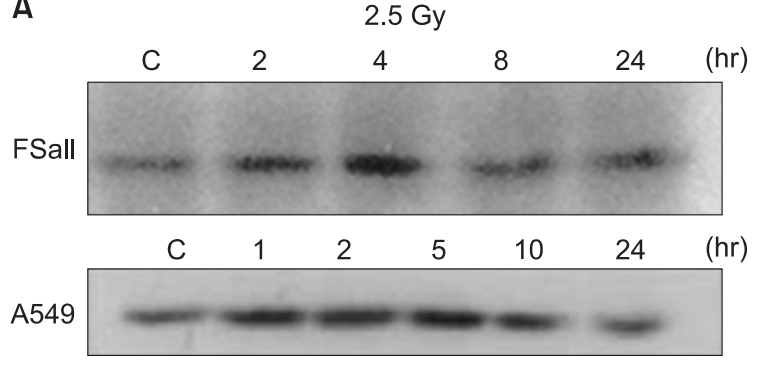

C Hypoxia

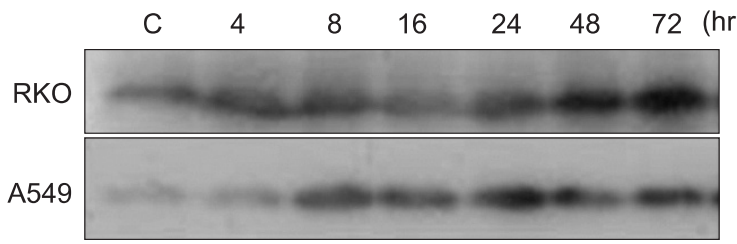

B

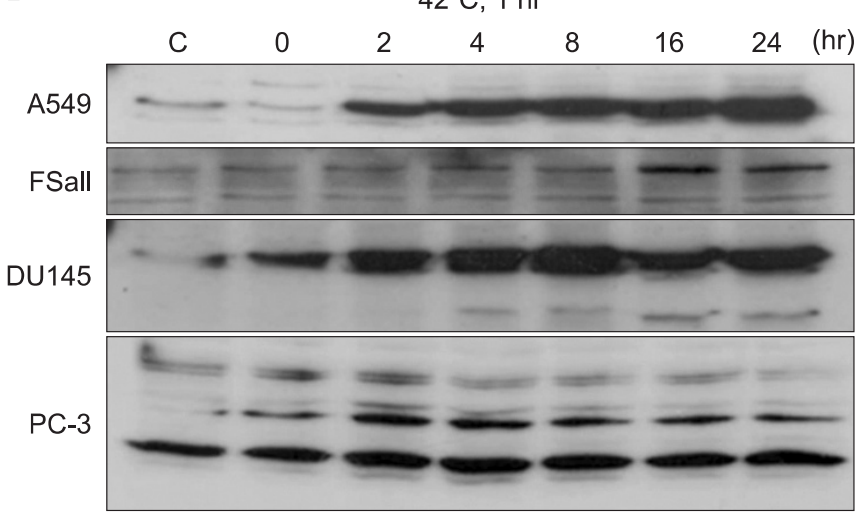

D Cisplatin, $2 \mu \mathrm{M} / \mathrm{hr}$

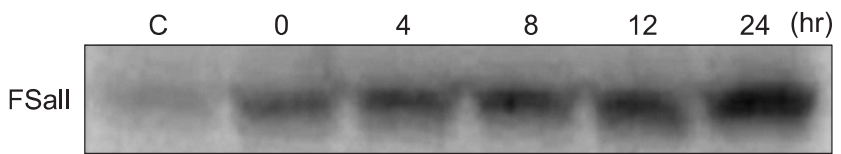

Fig. 2. Western blot analysis for the upregulation of NQ01 by various treatments. (A) Effect of 2.5 Gy irradiation on NQ01 levels in FSall cells and A549 cells (5). (B) Effects of heating at $42^{\circ} \mathrm{C}$ for 1 hour on the N001 levels in A549 cells, FSall cells, DU145 cells, and PC-3 cells (9). (C) Levels of N001 in RKO cells and A549 cells under continuous exposure to hypoxia. (D) Effects of 1 hour exposure to cisplatin at 2 $\mu \mathrm{M}$ on the N001 levels in FSall cells (7).

to a hydroquinone form, which is a far more potent alkalizing agent than the parent MMC [37-39]. N001 is ubiquitously expressed, but the levels of N001 in various human malignant tumors are significantly higher than that in adjacent normal tissues. For example, the N001 gene level in human hepatocarcinomas and hepatoblastomas is respectively 20-50 fold and 50-fold higher than that in normal liver tissues [40-42]. Interestingly, as mentioned above, DMM, DMF, fish oil, 13-cisretinoic acid, aspirin, and ibuprofen have been reported to upregulate N001 [26]. Importantly, various anti-cancer agents such as IR [3-6], chemotherapy drugs [7] and hyperthermia (heat shock) [8-11] and hypoxia (our unpublished observation) also increase N001 levels (Fig. 2). The fact that hypoxia upregulates N001 has a significant clinical implication because intratumor environment is intrinsically hypoxic, which may lead to upregulation of N001 in cancer cells. The mechanisms by which N001 expression is transcriptionally regulated by aforementioned factors have been investigated [10]. Several essential cis-elements, including an antioxidant response element (ARE), have been identified within the human N001 gene promoter region $[26,43]$. The ARE element, which is comprised of several nuclear transcription factors, is responsible for basal expression as well as induction of N001 not only by antioxidants but also by oxidants and xenobiotics [44]. It is highly probable that IR, heat shock, hypoxia, acidic environment and certain chemotherapy drugs activate N001 gene through similar mechanisms.

\section{Role of NOO1 in Anti-Cancer Effect of Bioreductive Drugs}

As mentioned in the preceding sections, recent experimental results by us as well as others have indicated that two-electron reduction of $\beta$-Lap mediated by N001 may be the initial step of the $\beta$-Lap-induced cell death pathway. In support of this view, the cellular sensitivity to $\beta$-Lap has been observed to be closely related to the level of N001 expression $[12,26,45,46]$. In addition, N001 inhibitors such as dicoumarol $[13,30,45]$ effectively inhibit $\beta$-Lap-induced cell death. Furthermore, stable transfection of $\mathrm{N} 001$ expression plasmid into cells lacking N001 increased the sensitivity of cells to $\beta$-Lap $[10,12]$ (Fig. 3). It has been observed that $1 \mathrm{~mol}$ of $\beta$-Lap could oxidize as many as $10 \mathrm{~mol}$ of NADH in 10 seconds or $100 \mathrm{~mol}$ of NADH in 10 minutes. Unlike the two-electron reduction products of other quinones, the hydroquinone form of $\beta$-Lap is unstable and rapidly undergoes autoxidation to the parent quinone 

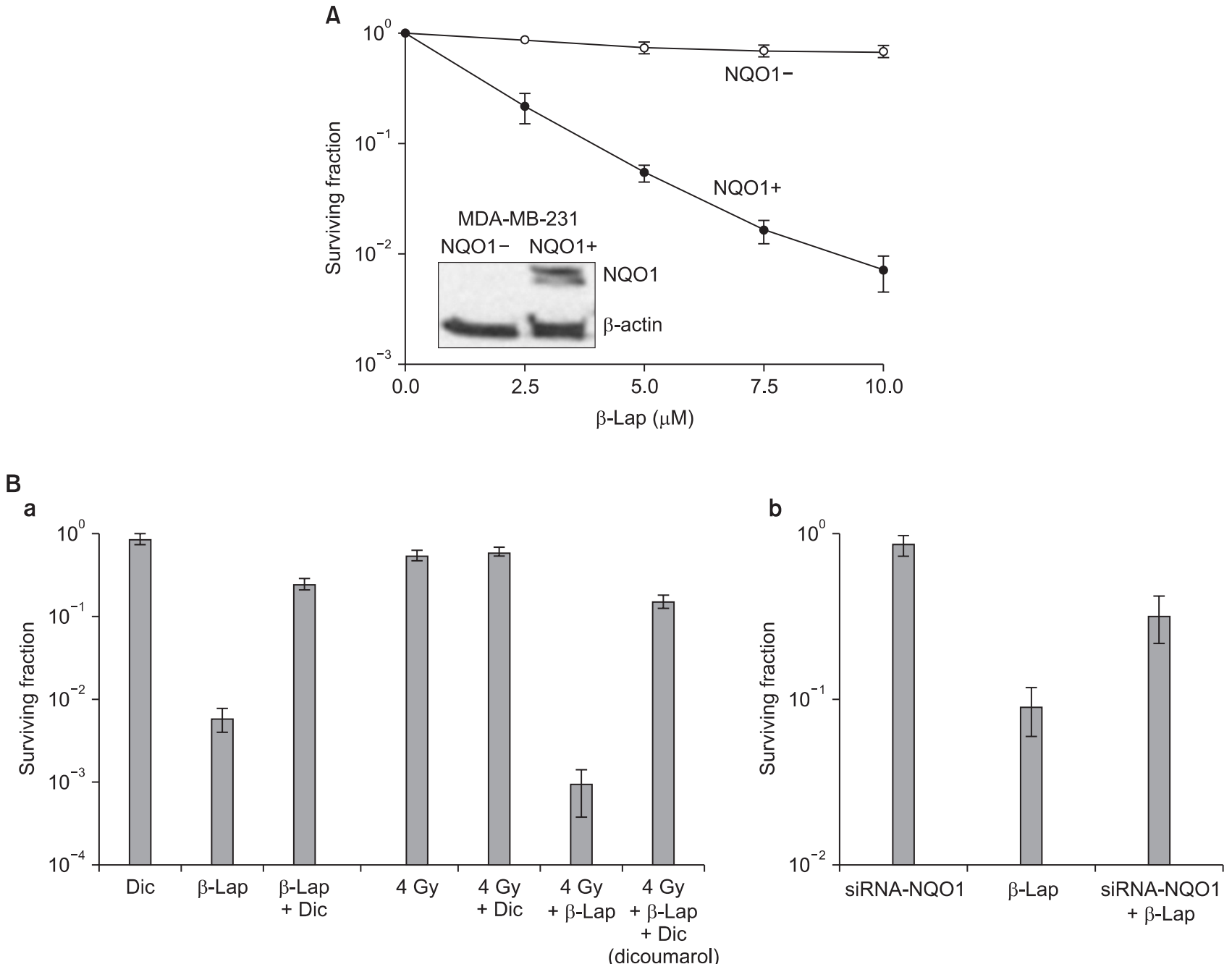

Fig. 3. Effect of N001 on the beta-lapachone ( $\beta$-Lap)-induced cell death. (A) Clonogenic death of N001-positive MDA-MB-231 and N001-negative MDA-MB-231 human breast cancer cells upon 4 hours incubation with different concentrations of $\beta$-Lap (11). (B) Effects of dicoumarol (N001 inhibitor) or siRNA-N001 on the $\beta$-Lap-induced clonogenic death in A549 cells (6).

[13]. It is believed that N001 induces "futile cycling" between quinone and hydroquinone forms of $\beta$-Lap utilizing NADH and $\operatorname{NAD}(\mathrm{P}) \mathrm{H}$ as electron sources. Consequently, NADH and $\mathrm{NAD}(\mathrm{P}) \mathrm{H}$ are severely depleted and $\mathrm{Ca}^{2+}$ is released from the endoplasmic reticulum into the cytosol after $\beta$-Lap treatment [12-15]. The increase in cytosolic $\mathrm{Ca}^{2+}$ is followed by depletion of ATP, depolarization of mitochondrial membrane, release of cytochrome $\mathrm{C}$, and activation of $\mathrm{Ca}^{2+}$ - dependent calpain or similar proteases. The unique features of apoptosis caused by $\beta$-Lap treatment is the degradation of p53 protein to a $40 \mathrm{kDa}$ fragment and the cleavage of poly (ADP-ribose) polymerase (PARP) to a $60 \mathrm{kDa}$ fragment instead of $89 \mathrm{kDa}$ fragment usually observed in caspase-mediated apoptosis. The cleavage of 553 and PARP appeared to be caused by $\mathrm{Ca}^{2+}$ dependent calpain. It was therefore proposed that $\beta$-Lap activates calpain-like proteases, thereby degrading vital proteins in the cells leading to caspase-independent apoptosis [12-15] (Fig. 1). In addition to the aforementioned molecular changes caused by depletion of NADH and NAD(P)H, generation of ROS may also be involved in $\beta$-Lap-induced cell death. It is likely that $\beta$-Lap (HQ), a hydroquinone formed as a result of two-electron reduction of $\beta$-Lap, may not directly oxidize back to $\beta$-Lap. Instead, $\beta$-Lap ( $\mathrm{HO}$ ) may be oxidized first to a one-electron reduced intermediate, i.e., semiquinone $\beta$-Lap (SO) ${ }^{--}$in a manner analogous to the oxidation of the hydroquinone form of MMC to the one-electron reduced form of MMC $[13,30,37$, 46-50] (Fig. 1). The active semiquinone $\beta$-Lap (SO)'- may then induce ROS and redox cycling and generate superoxides and 

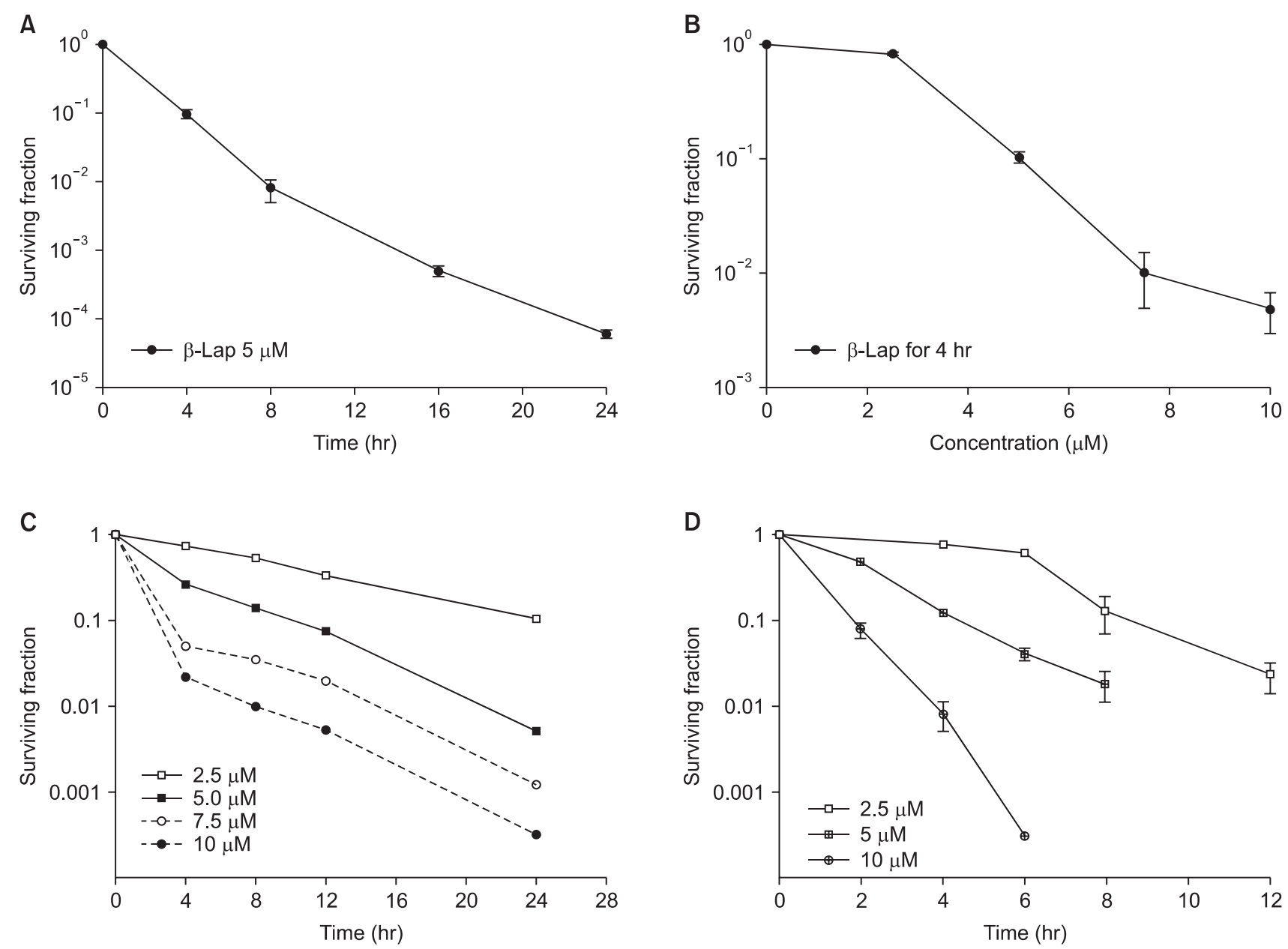

Fig. 4. Effect of beta-lapachone ( $\beta$-Lap) on the clonogenic survival of cells. (A) Effect of incubation with $5 \mu \mathrm{M} \beta$-Lap for various lengths of time on the clonogenic survival of A549 human lung cancer cells (6). (B) Effect of 4 hours incubation with different concentrations of $\beta$-Lap on the clonogenic survival of A549 cells (6). (C) Effect of incubation with different concentrations of $\beta$-Lap for various lengths of time on the clonogenic survival of PC3 prostate cancer cells. (D) Effect of incubation with different concentrations of $\beta$-Lap for various lengths of time on the clonogenic survival of FSall fibrosarcoma cells of mice (3).

$\mathrm{H}_{2} \mathrm{O}_{2}$, thereby triggering caspase-dependent apoptosis. In support of this notion, $\beta$-Lap has indeed been shown to induce caspase-dependent apoptosis and cleavage of PARP to an 89 kDa fragment under certain conditions [14]. In the cells lacking functional NQ01, such as HL-60 cells, $\beta$-Lap induces caspasedependent apoptosis by generating ROS [50].

\section{Cell Death by $\beta$-Lap Alone}

The cytotoxic effects of $\beta$-Lap alone have been investigated with a variety of cell lines. Fig. 4 shows the $\beta$-Lap-induced clonogenic deaths of A549 human lung epithelial cancer cells $(A, B), P C 3$ human prostate cancer cells ( $C$; our unpublished observation), and FSall mouse fibrosarcoma (D). It is shown that incubation with $5 \mu \mathrm{M} \beta$-Lap for 4 hours at $37^{\circ} \mathrm{C}$ reduced the clonogenic survival to about 10\% in most of the cell lines studied. The importance of the role of N001 in the $\beta$-Lapinduced cell killing is clearly demonstrated in Fig. $3 \mathrm{~A}$, which shows that the $\beta$-Lap sensitivity of human MDA-MB-231 breast cancer cells deficient of N001 (NOO1-) and that of MDA-MB-231 cells stably transfected with ngo1 (NO01+) (10). Incubation with $\beta$-Lap caused dose dependent clonogenic death in MDA-MB-231 (NO01+) cells whereas it caused little death in MDA-MB-231 (N001-). Dicoumarol is an inhibitor of NQ01 and treatment of cells with dicoumarol significantly protected cancer cells from $\beta$-Lap-induced death in various cell lines [3,5-8]. In agreement with these previous reports, Choi et al. [6] observed that dicoumarol significantly protected A549 human lung cancer cells from $\beta$-Lap-induced clonogenic death (Fig. 3B-a). Furthermore, suppression of N001 activity in 
A549 (N001+) cells by transfecting the cells with siRNA-N001 rendered the cells resistant to $\beta$-Lap (Fig. 3B-b). Collectively, these results clearly demonstrated that N001 plays a crucial role for the cell death caused by $\beta$-Lap. The mechanisms by which $N 001$ mediates $\beta$-Lap-induced cells death has already been discussed in the preceding sections. Note that, in addition to promoting futile cycling between quinone and hydroquinone forms of $\beta$-Lap, N001 may also be involved in other molecular and cellular changes caused by $\beta$-Lap such as cell cycle progression by affecting p53, p21 and cell cycle checkpoint as described in following sections.

\section{Cell Death by $\beta$-Lap in Combination with Irradiation}

It was previously reported that $\beta$-Lap increases the radioresponse of cells by inhibiting the repair of radiation-induced potentially lethal damage (PLD) $[1,19]$. Several subsequent reports demonstrated that $\beta$-Lap and IR interact in synergistic manner in killing cancer cells. Park et al. [3] reported that treatment of FSall fibrosarcoma cells of $\mathrm{C} 3 \mathrm{H}$ mouse with $\beta$-Lap prior to IR exposure caused little change in the response of the cells to irradiation. On the other hand, the radiation survival curves of the cells irradiated first and then immediately treated with $\beta$-Lap was much steeper than that of the cells exposed to IR alone (Fig. 5A). Importantly, as shown in Fig. 5B, $\beta$-Lap treatment applied 3-5 hours after irradiation was as effective as that applied immediately after irradiating the cells to increase the radiation-induced cell death. It was apparent that the combination of irradiation followed by $\beta$-Lap treatment was synergistic even when cells were treated with $\beta$-Lap as late as 10 hours after irradiation. As shown in Fig. 2, the N001 level in FSall cells markedly increased for 24 hours after 2.5 Gy irradiation. The authors therefore concluded that irradiation enhanced the response of tumor cells to $\beta$-Lap by increasing N001 activity. Similar observation was reported by Choi et al. [6] who studied the combined effect of irradiation and $\beta$-Lap using A549 lung cancer cells. The N001 level in the A549 cells was elevated for 24 hours after irradiation with 4 Gy and the irradiated cells were markedly sensitive to $\beta$-Lap for as long as 24 hours after irradiation. Essentially similar effect was obtained in a study with DU-145 prostate cancer cells that irradiation increased N001 level, thereby it sensitized the cells to subsequent treatment with $\beta$-Lap [5]. The notion that the post-irradiation increase in the response of cells to $\beta$-Lap is due to radiation-induced elevation of N001 was further supported by the observations that transfection of cells with N001-siRNA [6] or dicoumarol treatment [3,5] significantly inhibited the post-irradiation sensitization of cancer cells to $\beta$-Lap.

However, further studies revealed that the synergistic effect of irradiation and $\beta$-Lap to kill cancer cells is due not only to radiation-induced sensitization of cells to $\beta$-Lap, but also to the inhibition of sublethal radiation damage repair by $\beta$-Lap. It is well known that irradiation in two divided doses is less effective than that in a single dose with identical total dose because the sublethal radiation damage caused by the first dose is repaired by the time when the second irradiation is delivered. To investigate whether $\beta$-Lap affects the repair of sublethal radiation damage, cells were maintained in culture
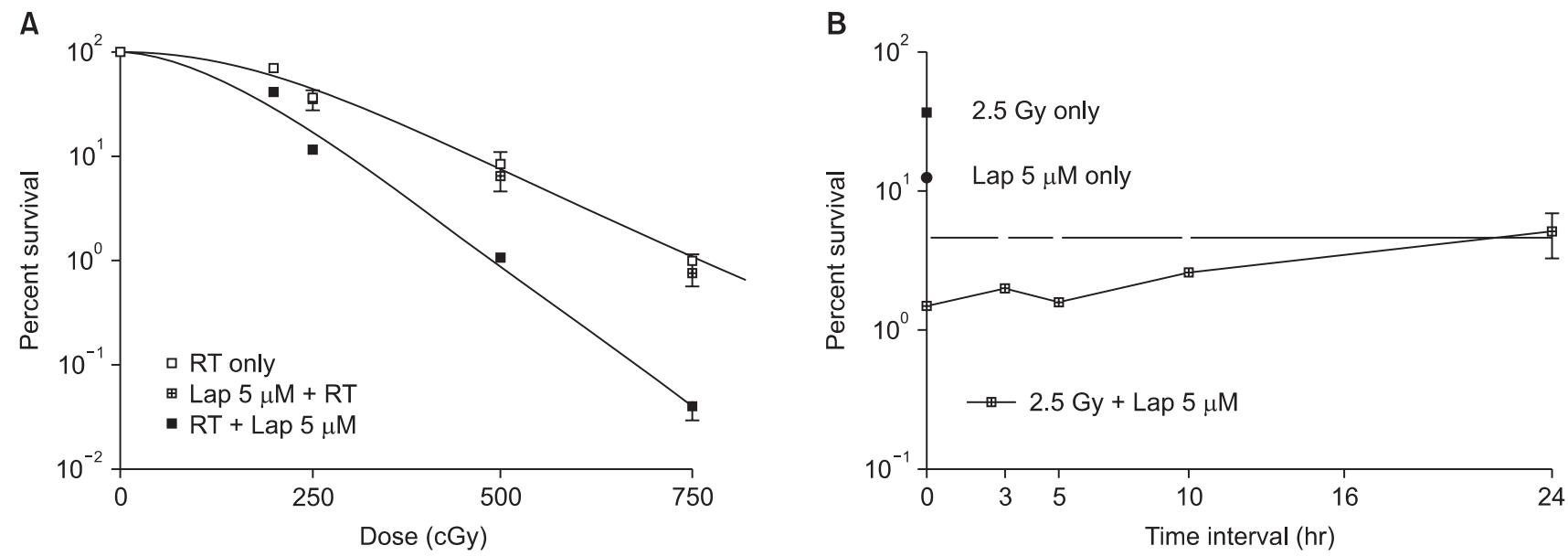

Fig. 5. Combined effect of beta-lapachone ( $\beta$-Lap) with radiation. (A) Survival curves of FSall cells exposed to various doses of irradiation alone or treated with $5 \mu \mathrm{M} \beta$-Lap for 4 hours immediately before or after irradiation (3). (B) Survival of FSall cells treated with 5 $\mu \mathrm{M} \beta$-Lap for 4 hours at various times after 2.5 Gy irradiation (3). RT, radiotherapy. 
media containing $\beta$-Lap during the interval between the two fractionated irradiation and the clonogenic survival was determined $[3,5]$. It was clear that $\beta$-Lap suppressed the repair of sublethal radiation damage that take place during the interval of two fractionated irradiation. We may conclude that the synergistic interaction between irradiation and $\beta$-Lap in killing cancer cells results from two distinct mechanisms: 1) irradiation increases the N001 activity, thereby it sensitizes cells to $\beta$-Lap, and 2) $\beta$-Lap suppresses the repair of sublethal radiation damage. The effectiveness of $\beta$-Lap in combination with radiotherapy in vivo has been studied. The suppression of tumor growth caused by $\beta$-Lap in combination with a single dose irradiation was significantly greater than that caused by $\beta$-Lap or irradiation alone in several animal tumor models $[3,4,6]$.

\section{Effects of $\beta$-Lap Alone or in Combination with Irradiation on Cell Cycle Progression}

$\beta$-Lap has been reported to kill cancer cells by interrupting cell cycle progression, thereby causing apoptosis $[1,17,18]$. We have elucidated the effects of $\beta$-Lap on various molecular signals known to be involved in cell cycle progression and apoptosis $[4,6]$. Interestingly, the expressions of p53 and p21, which are intimately involved in cell cycle progression and apoptosis, were markedly suppressed within 24 hours after cells were treated with $\beta$-Lap for 4 hours (Fig. 6). In view of the previous report that p53 is stabilized by N001 $[4,6]$, it is highly probable that depletion of N001 leads to disintegration of p53 molecule. We may then hypothesize that $\beta$-Lap, which is a substrate of N001, competes with p53 for N001and interrupts the N001-mediated stabilization of p53. It is likely that the decline in p21 activity resulted from the marked decline in p53. Interestingly, when irradiated cells were treated with $\beta$-Lap, the expression of $p 53$ and p21 was similar to that as in the cells treated with $\beta$-Lap alone, demonstrating that $\beta$-Lap nullified the effect of radiation to increase the expression of p53 and p21. Cyclin B1/cdc2 kinase is known to promote the progression of $\mathrm{G}_{2}$ cells to mitosis. It is a well known fact that irradiation causes $G_{2}$ arrest and increases cyclin B1/cdc2 kinase activity. Kim et al. [4] reported that an increase in the $G_{2}$ cell population after irradiation increased the cyclin B1/cdc2 kinase activity, which in turn, accelerated the exit of cells from the $G_{2}$ phase to mitosis and that the $\beta$-Lap completely prevented the radiation-induced $\mathrm{G}_{2}$ arrest as well as the radiation-induced upregulation of cyclin $\mathrm{B} 1 / \mathrm{ldc} 2$ kinase activity. It is tempting to conclude that the progressive decline in the $G_{2}$ cell population after $\beta$-Lap treatment removed the necessity for an increase in the cyclin B1/cdc2 kinase activity in irradiated cells. The mechanisms underlying the suppression of p53 activity and that in cyclin B1/cdc2 kinase activity by $\beta$-Lap in the irradiated cells remain to be investigated. Nevertheless, whatever the underlying mechanisms might be, it would be reasonable to speculate that the suppression of radiation-induced increase in $p 53$ expression and increase in cyclin B1/cdc2 kinase activity and radiation-induced $\mathrm{G}_{2}$ arrest by $\beta$-Lap are related to the synergistic effects of IR and $\beta$-Lap against cancer cells.

\section{Conclusion}

$\beta$-Lap is a potentially useful anti-cancer drug, particularly in combination with radiotherapy, although the mechanism underlying the $\beta$-Lap toxicity against cancer cells has been under investigation.
A

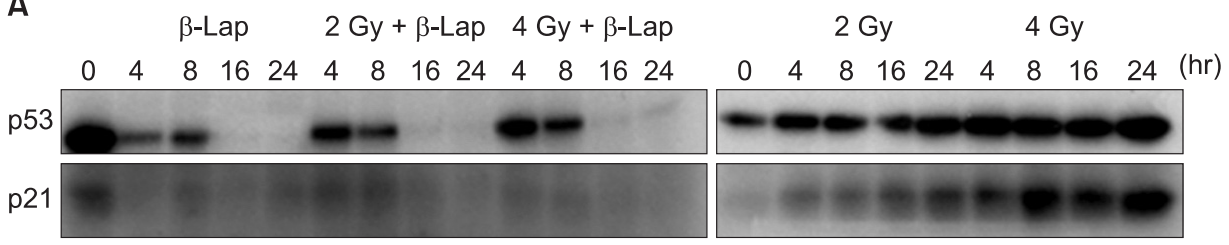

Cyclin B1/Cdc2 kinase

B

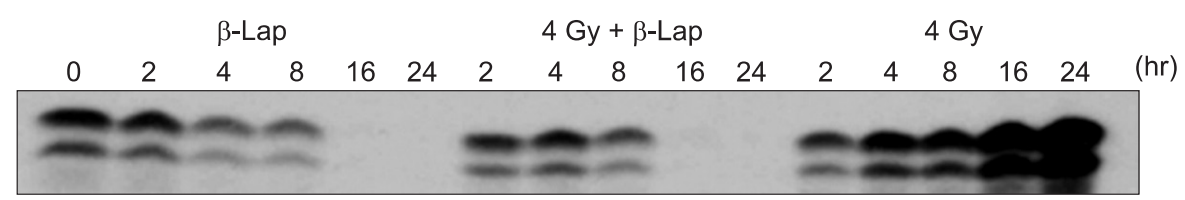

Fig. 6. Western blot analysis for the activities of p53 and p21 (A) and that of cyclin B1/cdc2 kinase (B) in the cells treated with irradiation alone, beta-lapachone ( $\beta$-Lap) alone and in combination. For the combined effect, the cells were first irradiated and then incubated with $5 \mu \mathrm{M} \beta$-Lap for 4 hours (4). 


\section{Conflict of Interest}

No potential conflict of interest relevant to this article was reported.

\section{References}

1. Pardee $A B$, Li YZ, Li CJ. Cancer therapy with beta-lapachone. Curr Cancer Drug Targets 2002;2:227-42.

2. Planchon SM, Wuerzberger $S$, Frydman $B$, et al. Beta-lapachone-mediated apoptosis in human promyelocytic leukemia (HL-60) and human prostate cancer cells: a p53-independent response. Cancer Res 1995;55:3706-11.

3. Park HJ, Ahn KJ, Ahn SD, et al. Susceptibility of cancer cells to beta-lapachone is enhanced by ionizing radiation. Int J Radiat Oncol Biol Phys 2005;61:212-9.

4. Kim EJ, Ji IM, Ahn KJ, et al. Synergistic effect of ionizing radiation and beta-Lapachone against RKO human colon adenocarcinoma cells. Cancer Res Treat 2005;37:183-90.

5. Suzuki M, Amano M, Choi J, et al. Synergistic effects of radiation and beta-lapachone in DU-145 human prostate cancer cells in vitro. Radiat Res 2006;165:525-31.

6. Choi EK, Terai $K_{1}$ Ji IM, et al. Upregulation of NAD(P)H:quinine oxidoreductase by radiation potentiates the effect of bioreductive beta-lapachone on cancer cells. Neoplasia 2007;9:63442.

7. Terai K, Dong GZ, Oh ET, et al. Cisplatin enhances the anticancer effect of beta-lapachone by upregulating N001. Anticancer Drugs 2009;20:901-9.

8. Park HJ, Choi EK, Choi J, et al. Heat-induced up-regulation of $\mathrm{NAD}(\mathrm{P}) \mathrm{H}$ :quinone oxidoreductase potentiates anticancer effects of beta-lapachone. Clin Cancer Res 2005;11:8866-71.

9. Song CW, Chae JJ, Choi EK, et al. Anti-cancer effect of bioreductive drug beta-lapachon is enhanced by activating N001 with heat shock. Int J Hyperthermia 2008;24:161-9.

10. Dong GZ, Youn H, Park MT, et al. Heat shock increases expression of $\mathrm{NAD}(\mathrm{P}) \mathrm{H}$ :quinone oxidoreductase (N001), mediator of beta-lapachone cytotoxicity, by increasing N001 gene activity and via Hsp70-mediated stabilisation of N001 protein. Int J Hyperthermia 2009;25:477-87.

11. Hori $T$, Kondo $T$, Lee $H$, Song CW, Park HJ. Hyperthermia enhances the effect of $\beta$-Lapachone to cause $\gamma H 2 A X$ formations and cell death in human osteosarcoma cells. Int J Hyperthermia 2011;27:53-62.

12. Planchon SM, Pink JJ, Tagliarino C, Bornmann WG, Varnes ME, Boothman DA. beta-Lapachone-induced apoptosis in human prostate cancer cells: involvement of N001/xip3. Exp Cell Res 2001;267:95-106.

13. Pink JJ, Planchon SM, Tagliarino C, Varnes ME, Siegel D, Boo- thman DA. NAD(P)H:quinone oxidoreductase activity is the principal determinant of beta-lapachone cytotoxicity. J Biol Chem 2000;275:5416-24.

14. Pink JJ, Wuerzberger-Davis $S$, Tagliarino $C$, et al. Activation of a cysteine protease in MCF-7 and T47D breast cancer cells during beta-lapachone-mediated apoptosis. Exp Cell Res 2000;255:144-55.

15. Tagliarino C, Pink JJ, Dubyak GR, Nieminen AL, Boothman DA. Calcium is a key signaling molecule in beta-lapachonemediated cell death. J Biol Chem 2001;276:19150-9.

16. Wuerzberger SM, Pink JJ, Planchon SM, Byers KL, Bornmann WG, Boothman DA. Induction of apoptosis in MCF-7:WS8 breast cancer cells by beta-lapachone. Cancer Res 1998 58:1876-85.

17. Huang $L$, Pardee $A B$. beta-lapachone induces cell cycle arrest and apoptosis in human colon cancer cells. Mol Med 1999;5: 711-20.

18. Li $Y$, Sun $X$, LaMont JT, Pardee AB, Li CJ. Selective killing of cancer cells by beta-lapachone: direct checkpoint activation as a strategy against cancer. Proc Natl Acad Sci U S A 2003; 100:2674-8.

19. Boothman DA, Trask DK, Pardee AB. Inhibition of potentially lethal DNA damage repair in human tumor cells by betalapachone, an activator of topoisomerase I. Cancer Res 1989; 49:605-12.

20. Hueber A, Esser P, Heimann K, Kociok N, Winter S, Weller $M$. The topoisomerase I inhibitors, camptothecin and betalapachone, induce apoptosis of human retinal pigment epithelial cells. Exp Eye Res 1998;67:525-30.

21. Li CJ, Averboukh L, Pardee AB. beta-Lapachone, a novel DNA topoisomerase I inhibitor with a mode of action different from camptothecin. J Biol Chem 1993;268:22463-8.

22. Weller $M$, Winter $S$, Schmidt $C$, et al. Topoisomerase-l inhibitors for human malignant glioma: differential modulation of p53, p21, bax and bcl-2 expression and of CD95-mediated apoptosis by camptothecin and beta-lapachone. Int J Cancer 1997;73:707-14.

23. Frydman $B$, Marton $\sqcup$, Sun JS, et al. Induction of DNA topoisomerase II-mediated DNA cleavage by beta-lapachone and related naphthoquinones. Cancer Res 1997:57:620-7.

24. Krishnan P, Bastow KF. Novel mechanism of cellular DNA topoisomerase II inhibition by the pyranonaphthoquinone derivatives alpha-lapachone and beta-lapachone. Cancer Chemother Pharmacol 2001;47:187-98.

25. Li CJ, Li YZ, Pinto AV, Pardee AB. Potent inhibition of tumor survival in vivo by beta-lapachone plus taxol: combining drugs imposes different artificial checkpoints. Proc Natl Acad Sci U S A 1999;96:13369-74.

26. Begleiter A, Fourie J. Induction of N001 in cancer cells. Methods Enzymol 2004;382:320-51. 
27. Joseph $P, X i e T, X u Y$, Jaiswal $A K$. NAD(P)H:quinone oxidoreductase 1 (DT-diaphorase): expression, regulation, and role in cancer. Oncol Res 1994;6:525-32.

28. Joseph $\mathrm{P}$, Jaiswal AK. NAD(P)H:quinone oxidoreductase1 (DT diaphorase) specifically prevents the formation of benzo[a] pyrene quinone-DNA adducts generated by cytochrome P4501A1 and P450 reductase. Proc Natl Acad Sci U S A 1994; 91:8413-7.

29. Jaiswal AK. Characterization and partial purification of microsomal NAD(P)H:quinone oxidoreductases. Arch Biochem Biophys 2000;375:62-8.

30. Cullen JJ, Hinkhouse MM, Grady M, et al. Dicumarol inhibition of NADPH:quinone oxidoreductase induces growth inhibition of pancreatic cancer via a superoxide-mediated mechanism. Cancer Res 2003:63:5513-20.

31. Monks TJ, Hanzlik RP, Cohen GM, Ross D, Graham DG. Quinone chemistry and toxicity. Toxicol Appl Pharmacol 1992;112:2-16.

32. Riley RJ, Workman P. DT-diaphorase and cancer chemotherapy. Biochem Pharmacol 1992;43:1657-69.

33. Rauth AM, Goldberg Z, Misra V. DT-diaphorase: possible roles in cancer chemotherapy and carcinogenesis. Oncol Res 1997:9:339-49.

34. Ross D, Siegel D. NAD(P)H:quinone oxidoreductase 1 (NOO1, DT-diaphorase), functions and pharmacogenetics. Methods Enzymol 2004;382:115-44.

35. Talalay P. Mechanisms of induction of enzymes that protect against chemical carcinogenesis. Adv Enzyme Regul 1989; 28:237-50.

36. Jaiswal AK. Jun and Fos regulation of $N A D(P) H$ : quinone oxidoreductase gene expression. Pharmacogenetics 1994;4:1-10.

37. Keyes SR, Fracasso PM, Heimbrook DC, Rockwell S, Sligar SG, Sartorelli AC. Role of NADPH:cytochrome c reductase and DTdiaphorase in the biotransformation of mitomycin $\mathrm{C} 1$. Cancer Res 1984;44:5638-43.

38. Pan SS, Andrews PA, Glover CJ, Bachur NR. Reductive activation of mitomycin $\mathrm{C}$ and mitomycin $\mathrm{C}$ metabolites catalyzed by NADPH-cytochrome $\mathrm{P}-450$ reductase and xanthine oxidase. J Biol Chem 1984;259:959-66.

39. Hodnick WF, Sartorelli AC. Reductive activation of mitomycin C by NADH:cytochrome b5 reductase. Cancer Res 1993;53:4907-
12.

40. Siegel D, Franklin WA, Ross D. Immunohistochemical detection of $\mathrm{NAD}(\mathrm{P}) \mathrm{H}$ :quinone oxidoreductase in human lung and lung tumors. Clin Cancer Res 1998;4:2065-70.

41. Belinsky $M$, Jaiswal AK. NAD(P)H:quinone oxidoreductase 1 (DT-diaphorase) expression in normal and tumor tissues. Cancer Metastasis Rev 1993;12:103-17.

42. Cresteil $T$, Jaiswal AK. High levels of expression of the NAD(P)H: quinine oxidoreductase (N001) gene in tumor cells compared to normal cells of the same origin. Biochem Pharmacol 1991; 42:1021-7.

43. Long DJ 2nd, Gaikwad A, Multani $A$, et al. Disruption of the $\mathrm{NAD}(\mathrm{P}) \mathrm{H}$ :quinone oxidoreductase 1 (N001) gene in mice causes myelogenous hyperplasia. Cancer Res 2002;62:3030-6.

44. Dhakshinamoorthy $S$, Jaiswal AK. Functional characterization and role of INrf2 in antioxidant response element-mediated expression and antioxidant induction of $\mathrm{NAD}(\mathrm{P}) \mathrm{H}$ :quinone oxidoreductase1 gene. Oncogene 2001;20:3906-17.

45. Winski SL, Swann E, Hargreaves RH, et al. Relationship between $\mathrm{NAD}(\mathrm{P}) \mathrm{H}$ :quinone oxidoreductase 1 (N001) levels in a series of stably transfected cell lines and susceptibility to antitumor quinones. Biochem Pharmacol 2001;61:1509-16.

46. Docampo R, Cruz FS, Boveris A, Muniz RP, Esquivel DM. betaLapachone enhancement of lipid peroxidation and superoxide anion and hydrogen peroxide formation by sarcoma 180 ascites tumor cells. Biochem Pharmacol 1979;28:723-8.

47. O'Brien PJ. Molecular mechanisms of quinone cytotoxicity. Chem Biol Interact 1991;80:1-41.

48. Boveris A, Docampo R, Turrens JF, Stoppani AO. Effect of beta-lapachone on superoxide anion and hydrogen peroxide production in Trypanosoma cruzi. Biochem J 1978;175:431-9.

49. Chau YP, Shiah SG, Don MJ, Kuo ML. Involvement of hydrogen peroxide in topoisomerase inhibitor beta-lapachone-induced apoptosis and differentiation in human leukemia cells. Free Radic Biol Med 1998;24:660-70.

50. Molina Portela MP, Stoppani AO. Redox cycling of beta-lapachone and related o-naphthoquinones in the presence of dihydrolipoamide and oxygen. Biochem Pharmacol 1996;51: 275-83. 